\title{
Professional Bureaucracy and Health Care Managers' Planned Change Strategies: Governance in Swedish Health Care'
}

\section{Jörgen Andreasson ${ }^{2}$}

PhD student, Department of Work Life and Social Welfare, University of Borås, Sweden

I Erik Ljungar

PhD, Department of Work Life and Social Welfare, University of Borås, Sweden

I Linda Ahlstrom

PhD, The Sahlgrenska Academy, University of Gothenburg, Sweden

I Jonas Hermansson

PhD, Research and Development Department, Angered Hospital, Sweden

I Lotta Dellve

Professor, Department of Sociology and Work Science, University of Gothenburg, Sweden

\begin{abstract}
To increase efficiency and quality, process development has been implemented in many Swedish hospitals. These hospitals are usually organized as professional bureaucracies in which health care managers have limited decision control. The new governance principles has been implemented without removing bureaucratic elements. This study analyzes how managers implement planned change in these professional bureaucracies, considering if managers coaching style, organizational preconditions, implementation strategy, appraisal of change and clinic autonomy, is associated with health care process quality (HPQ). The study is based on interviews with health care managers and longitudinal assessments of HPQ. The results revealed significant differences between coaching style, organizational preconditions, and HPQ over time. The conclusion is that leadership and preconditions is of importance for the health care manager's ability to work with planned change, as that the health care managers understand how management methods, governance principles, and professional bureaucracies work in practice.
\end{abstract}

\section{KEYWORDS}

Bureaucracy / health care organizations / health care managers / implementation / lean management I planned change

\section{INTRODUCTION}

ver the last few decades, increasing health care expenditures have forced health care organizations, such as hospitals, to find new ways to run their operations. One focus has been to increase efficiency and quality by means of process development,

\footnotetext{
${ }^{1}$ You can find this text and its DOI at https://tidsskrift.dk/njwls/index

${ }^{2}$ Corresponding author: Jorgen.andreasson@vgregion.se
} 
seeking to improve patient care in the health care system (Mazzocato et al., 2010). A method that over the last few years has started to spread and now is being tested in the Scandinavian health care is Lean production (Andersen et al., 2015; Dammand et al., 2014; Edwards et al., 2011; Kamp et al., 2016). In Sweden, over 85\% of the hospitals claims they are working according to Lean in their daily operations (Weimarsson, 2011). Previous research into methods for planned change, such as Lean management, has demonstrated that implementing new ideas and methods can be difficult and that the risk of failure is often great (Lee \& Alexander, 1999; Sederblad, 2013). This is due to factors such as governance principles, organizational type, and the manager's daily working situation that either can contribute or counteract the organizations possibilities to work with planned change. However, an important success factor when implementing Lean management or other ways to organize work is effective leadership (Holden, 2011; Kotter, 1996; Robertson et al., 1993). An earlier study found that the Swedish health care manager's main strategy to implement Lean or similar management concepts was through a mediating or coaching leadership (Andreasson et al., 2015). For the purpose of this paper, we have operationalized the coaching leadership style, for each of the individual managers, into variables described by the managers important for success in implementing Lean or processes. In order to detect associations between individual variables and results, we have constructed the outcome measure in health care process quality (HPQ). Therefore, in line with this, our aim of the present study is to investigate if health care managers, coaching style, preconditions, implementation strategy, appraisal of change, and clinic autonomy is associated with HPQ measured in HPQ.

\section{BACKGROUND}

\section{Governance and management principles in Swedish health care}

In recent years, Swedish health care organizations have been influenced by various management or governance principles, among which new public management (NPM) and Lean management have been prominent (Berlin \& Kastberg, 2011; Weimarsson, 2011). These principles differ somewhat, but are all supposed to both decentralize and increase steering power in health care organizations to varying degrees.

Some of these principles were influenced by private-market concepts (Berlin \& Kastberg, 2011), meaning that particular units in public health care organizations bought health care services from both public and private health care providers. One method implemented in health care organizations is, for example, management by objectives, the introduction of which was seen as appropriate in a system that has difficulties controlling input, that is, optimal patient flow (Hall, 2013). Another important characteristic is the decentralization of responsibilities, leading to the increased delegation of tasks. This is sometimes seen as part of a larger trend in many countries in which public organizations, such as hospitals, are implementing principles of market governance as a steering or management method (Bevir, 2012). The increased delegation of tasks has led to difficulties for governments and authorities seeking to control the quality of the health care system output (Hall, 2013; Tengblad, 2003).

Lean management is not a new concept in Sweden, the current wave of interest is the second in recent decades (Björkman \& Lundqvist, 2013, pp. 18-47, quoted in 
Sederblad, 2013; Movitz \& Sandberg, 2013). The difference is that even public organizations, not least hospitals and other health care organizations, are now trying to implement it. A problem encountered when implementing Lean management is that hospitals sometimes display more interest in the ideology behind the concept and its standards than in actually implementing the standards in their work organizations. It has become fashionable to talk of such reform, even though it is not always implemented in practice (Berlin \& Kastberg, 2011; Brunsson, 2006). Most Swedish hospitals claim to be working on Lean management (Weimarsson, 2011), using Lean with the intention to improve both care quality and financial efficiency (Andreasson et al., 2015; Dellve et al., 2013; Mazzocato et al., 2010). A significant characteristic of Lean management work is that it is undertaken in processes where the organization will prioritize and streamline horizontal, but not vertical flows (Björkman \& Lundqvist, 2013; Dellve et al., 2013).

Lean management strives to break up the traditional bureaucratic organization of work that has been historically significant in many Swedish hospitals. Achieving a flattened organizational form is favored in Lean implementation, because this is supposed to foster more competent and efficient managers and slimmer organizations with fewer middle line managers. Lean management also entails increased task standardization. This depends on the existence of certain well-established methods to organize work processes, meaning that more or less the same management principles are implemented in, for example, car factories and health care organizations (Berlin \& Kastberg, 2013; Dellve et al., 2013; Björkman \& Lundqvist, 2013). Lean management is also supposed to encourage teamwork, with team members undertaking different tasks in small groups. Team members thereby have opportunities to influence their work conditions by reporting to their team leader and/or manager, improving their quality of work through communication (Berlin \& Kastberg, 2011; Dellve et al., 2013).

\section{The professional bureaucratic organization}

In the professional bureaucracy, the power resources of professional workers are salient, meaning that these workers have great autonomy and freedom to implement their work based on their knowledge and professional skills (Mintzberg, 1983). The professional bureaucratic organizational form differs from what Mintzberg refers to as the machine bureaucracy, the traditional form consistent with Max Weber's (1964) classical definition. The machine bureaucracy is a hierarchical form of organization in which both managers and employees have well-defined work positions and specified duties, and work processes are coordinated by predesigned standards that determine what is to be done.

In the professional bureaucracy, the professional workers consists of specialists with comprehensive control over their own work, which means that the managers often have a hidden role in implementing the organization's goals. In Mintzberg's (1983) model, the function of managers is primarily to support the professional workers. The work standards and institutional scripts or norms the professional workers follow originate outside the organization's own structure, for example, from self-governing associations, other workplaces, and universities, or are defined by other authorities. This also influences the power of managers to conduct their work and, in particular, their ability to steer professional workers. The authority of professional organizations relies more on the 
professions and the power of expertise than on top-down steering. The professionals also work autonomously from their colleagues but close to their clients, for example, patients (Glouberman \& Mintzberg, 2001; Mintzberg, 1983). In the case of health care, professionals have well-defined skills and have learned how to undertake their tasks in a professional and specific manner (Berlin \& Kastberg, 2011; Glouberman \& Mintzberg, 2001).

Implementing new ideas in the professional bureaucracy can be difficult, depending on the professional workers' potential reluctance to adapt to change (Mintzberg, 1983). The professional bureaucracy has a clear bottom-up decision-making structure in which both independent professionals and strategic managers must agree to proposed changes. This makes the professional bureaucracy a rigid structure that functions well in producing standardized outputs but is slow to adapt to change and alter production methods (Mintzberg, 1983). The power to change organizations is according to Mintzberg (1983) conditional on the manager's ability to involve employees in development work. Manager knowledge of change management is also crucial for the possibility of working with organizational development (Andreasson et al., 2015; Glouberman \& Mintzberg, 2001; Kotter, 1996; Mintzberg, 1983).

Organizational change can become a goal in itself, in which the management techniques implemented are part of a general fashion or reform movement (Brunsson, 2006; Brunsson \& Olsen, 1993; Czarniawska, 2008; Czarniawska \& Sevón, 1996). Institutional analysis has demonstrated that organizations imitate their environments because they experience pressure from the institutional environment to organize work in new ways in order to increase their legitimacy (DiMaggio \& Powell, 1983). It has become fashionable in many industries and public organizations to implement Lean management (Berlin \& Kastberg, 2011; Sederblad, 2013), and health care organizations, see the implementation of Lean and similar management principles as a way to increase their legitimacy in the institutional environment.

The problem is thus that the managers whose task it is to implement these new management standards and production processes sometimes face resistance from the professional workforce of doctors, nurses, etc. Lean management tends to be only a fashion or ideology in which the organization talks a lot about implementation to boost efficiency, but does not actually succeed in doing so in practice. According to Brunsson and Olsen (1993), organizations can sometimes succeed in implementing reforms if they do not overly disturb core activities, in what is often referred to as decoupling (Brunsson, 1986; Brunsson \& Olsen, 1993; Meyer \& Rowan, 1977). Lean management principles can be successfully implemented if the organization decouples its daily routines from the organizational structure implied by the legitimized order. At the same time, the organization must ensure that the parts of Lean management that are actually implemented in daily operations do not overly disturb or interfere with the professional workers' often well-established work routines (Brunsson, 2006). In analyzing organizational change in the Swedish health care system, this study takes its departure in Mintzberg's concept of the professional bureaucratic organization (Glouberman \& Mintzberg, 2001; Mintzberg, 1983).

\section{The health care manager's everyday working conditions}

Studies of Swedish health care managers have found that their work conditions are characterized by complexity, high workload, and multiple administrative duties. This 
means they have limited time to address development issues and have difficulties making decisions independently (Andersson et al., 2015; Arman et al., 2012; Tengblad, 2003). The health care management profession also has problems with stress, sickness absence, and endurance, especially when working on development issues (Skagert et al., 2008; Tengblad, 2003). This work environment also affects the health care manager's employees, causing difficulties in motivating them to work on organizational development and change (Ohlsson \& Rombach, 1998; Skagert et al., 2008). The frequency of which tasks are delegated by health care managers to professional workers is often high in Swedish health care organizations (Andreasson et al., 2015; Tengblad, 2003), even though major decisions are made higher up in the organization (Edling \& Sandberg, 2013). Through these mechanisms, health care organizations simultaneously become both hierarchical and non-hierarchical (Edling \& Sandberg, 2013). An effect of this is that health care managers lose some of their direct power to control and manage the work conditions and their employees (Andreasson et al., 2015). The employees are traditionally used to working in autonomous groups, and managers trying to implement new strategies or working methods in daily operations often generate resistance. In particular, the relative independence of professional workers such as doctors and nurses gives them power to question and sometimes resist ideas and suggestions from their managers. Implementing Lean management in health care organizations therefore entails constant negotiation with employees regarding what should be implemented, at what pace, how, and to what extent. In negotiations about implementing changes, it is sometimes difficult for health care managers to convince professional workers that implementing Lean management and production will benefit them in their daily work routines (Andreasson et al., 2015).

\section{Power to change}

The main task of health care managers in successfully implementing Lean management or similar processes in health care organizations is to encourage, motivate, and empower the professional workers to participate in and contribute to the development work (Andreasson et al., 2015; Cummings et al., 2010). To achieve significant change, health care managers must use management skills to make all those involved interested in the proposed change and to guide them through the process (Kotter, 1996). To realize such leadership, managers need to apply a coaching approach based on trusting relationships with the professional workers. This means that the managers must respect the professional workers' skills and established work routines, giving them the freedom to act independently, and avoid micromanaging (Andreasson et al., 2015; Vesterinen et al., 2012). It has been demonstrated that some health care managers delegate developmental tasks to professional workers without following up on the results and without checking whether they possess the knowledge needed to undertake the delegated tasks (Andreasson et al., 2015). There are examples of Lean implementation in which the professional workers and employees actually perceived that their work quality improved in many respects due to their managers' better first-line leadership (Dellve et al., 2013). In these cases, a key success factor for the implementation was that the health care managers had a positive appraisal of addressing development issues in a substantial way (Andreasson et al., 2017).

Studies also demonstrate that health care managers' positive attitudes toward change can cause their employees to have more positive attitudes toward working with change 
(Mathena, 2002), helping to create a change-friendly work environment (Damanpour, 1991). Other factors demonstrated to be important for health care managers' ability to implement change are support from upper management and management colleagues, organizational resources, and support from the professional workers in the organization (Andreasson et al., 2017; Lachinger et al., 2006; Plsek \& Wilson, 2001; Skytt, 2007). Also, positive support from managers and colleagues can motivate all those involved in the change process, increasing the chances of implementing actual change (Demerouti \& Bakker, 2011). Organizational support, such as access to people skilled in change management or people powerful enough to implement the change, has also been associated with improved quality and performance in health care (Lachinger et al., 2006; Plsek \& Wilson, 2001). Being a health care manager in a large clinic or hospital can also be a positive factor when implementing Lean management or similar. In such case, the managers can oversee most patient needs within their own organizations, making it easier to develop and control the patient processes. These managers have needed resources available within their own organizational boundaries, so they can change the processes as needed without negotiating with other clinics or organizations. This means a higher degree of clinic autonomy (Andreasson et al., 2015).

In summary, implementing new ideas in professional bureaucracies poses many challenges. Our aim of this study is to analyze if health care managers' coaching style, preconditions, implementation strategy, appraisal of change, and clinic autonomy is associated with HPQ measured in HPQ.

\section{DATA AND METHODS}

Managers and employees working in five hospitals were included. The hospitals were ranging from 100 to 420 beds in size and located in various parts of Sweden. Two of the hospitals implemented self-constructed management models to improve their work processes, and three claimed they implemented Lean management. Decisions to implement Lean management or self-constructed management models were made in 2011 by the hospital management at each hospital. Units involved in the process of caring for acutely ill patients were chosen, that is, the emergency/ambulance, intensive care, medicine, and surgical clinics/units. The data were gathered from interviews with first- and second-line managers and questionnaires to employees working in the units they were in charge of.

The managers $(n=31)$ were interviewed between September 2012 and January 2013. For the purpose of this paper, we (1) excluded, three of the managers who were included in the previous paper because their units were not taking part in the questionnaire study; and (2) included four other first-line managers from the same population, also interviewed during the same time period. The mean age of the interviewed managers was 50 years (range, 33-62 years) and they had an average of seven years of work experience as managers (range, 1-17 years). Of the first-line managers, one was a physician and 19 were registered nurses; of the second-line managers, seven were physicians and five were registered nurses.

A questionnaire was answered by employees at three times: 2012 (T0, n = 1602, response rate $54 \%$ ) and $2013(\mathrm{~T} 1, \mathrm{n}=1548$, response rate $59 \%)$. In 2014, at $\mathrm{T} 2$, the questionnaire was distributed only to those who had previously completed the questionnaire in either 2012 or 2013 and were still employed in the same position as at T0 or 
T1 (T2, $\mathrm{n}=947$ response rate $67 \%$ ). The respondents at (T0) consisted of $28 \%$ assistant nurses, $44 \%$ registered nurses, $26 \%$ physicians, $1.9 \%$ secretaries, and $0.1 \%$ other respondents, for example, psychologist or physiotherapist.

\section{Qualitative interviews and analysis}

We used an interview form with prepared main questions, and in line with the grounded theory (Charmaz, 2006), the initial questions were wide ranging, for example: How do you work on developing and implementing Lean or other management processes? What are your strategies and approaches to increase employee engagement in the development of Lean or other management models? Based on the manager's answers to the initial questions, supplementary questions were asked to obtain more detailed descriptions. Each interview lasted about 60 minutes. Theoretical sufficiency (Charmaz, 2006) was reached after 20 interviews, but we performed 11 additional interviews to validate our findings.

In line with grounded theory, the data were collected and analyzed simultaneously. This increased the theoretical sensitivity in the follow-up questions during the interviews. During the coding process, theoretical notes were continuously written to develop theoretical sensitivity and challenge prior understandings of the research questions. All data were analyzed manually and the interviews were transcribed word-by-word, five at a time, and analyzed line by line. The first step of the coding procedure was open coding, in which the managers' statements were labelled with codes close to the data. The second step was focused coding, in which the open codes were compared with each other, the raw data, and the theoretical notes. This comparison generated more abstract categories that corresponded to clusters of codes; these categories were compared with each other and with the original data.

The coding process identified a core category in 'coaching for participation', which emerged from the categories 'negotiating and building participation' and 'sustaining integrity in adaptation and translation'. These categories were related to the subcategories 'mindfully adopting management models', 'low-key introduction of change', 'pushing and pulling to spark employee interest', and 'empowering by sharing or dumping responsibility'. These categories together formed the manager's strategies for implementing Lean management and processes in their units. This study has been described in detail in another paper (Andreasson et al., 2015).

\section{Operationalization of qualitative categories}

The previous interview study also revealed five significant areas in which the managers could succeed in implementing Lean management or processes (Andreasson et al., 2015). For the purpose of this study, we operationalized these five areas into the variables health care managers' coaching style, appraisal of change, organizational preconditions, implementation strategy, and perceived degree of clinic autonomy. We then assessed the manager's performance and opportunities within each variable, to be able to discover potential differences between the managers within and between the categories. In this process, we created internal grading points within each category. In the 
categories coaching style and appraisal of change, we used a grading scale of 1, 2, or 3 points. For the categories, organizational preconditions, implementation strategy, and degree of clinic autonomy, we only graded the extremes, for example, 3 for having the preconditions or 1 for not having the precondition. Each grading is exemplified according to the description below.

\section{Coaching style}

This category included integrated coaching, immature coaching, or distanced coaching/ dumping. Integrated coaching was based on involvement in the employees' work as a facilitator and initiator of various kinds of development work.

3 points: When a group of employees was ready to continue the development work independently, the manager delegated the work to the group. Managers applying integrated coaching could reason about different stages of developmental maturity in their employee groups, balancing the pace of implementation of the groups.

2 points: Managers implementing immature coaching could reason theoretically about their own involvement in employee groups, the developmental maturity of employees, and how to delegate responsibilities, but could cite few examples of how they actually did so.

1 point: Managers applying distanced coaching/dumping were not involved in their employee groups, conducted no discussions of employee developmental maturity, and had no implementation plan. Instead, they dumped the whole question of development on their employees and clearly explained that it was their responsibility to implement, for example, Lean management. These managers did not interfere in this work, as their work was just to maintain preconditions for the work group.

\section{Appraisal of change}

This category contained positive-driving, positive passive, and negative passive.

3 points: The positive-driving managers were clearly positive toward change and made active efforts to convince their employees to work to advance it.

2 points: The positive-passive managers had positive thoughts about, for example, Lean management, could see that it offered good ideas in theory and for many companies, though maybe not in health care, but made no efforts to really apply Lean management/processes in their departments.

1 point: The negative-passive managers expressed their negative thoughts about Lean management and processes and had no intention to implement them, possibly working against implementation instead. The negative to change but driving category was not found among the studied managers.

\section{Organizational preconditions}

Organizational preconditions were grouped as good or poor.

3 points: Managers with good organizational preconditions were ones who said that they had access to or could be helped by people skilled in the change process, had 
people nearby (e.g., other managers and employees) who were positive toward change, and/or had time allocated for development work.

1 point: The managers who lacked the above resources or preconditions and/or worked in departments characterized by high patient volumes and little time allocated for development work were classified as having poor preconditions.

\section{Implementation strategy}

Implementation strategy was categorized as having or not having an implementation strategy.

3 points: The managers who said that they had a strategy for implementing Lean management or had relevant processes in their departments or clinics were classified as having a strategy.

1 point: The managers who believed that Lean management or processes were inapplicable to their departments or clinics, or who believed that they already worked in this way and had no intention to implement Lean management or processes, were classified as having no strategy.

\section{Degree of clinic autonomy}

This category was grouped as high, low, or none.

3 points: Managers of large clinics with specific patient categories and sufficient resources to handle the patient's whole treatment within the clinic, often using their own doctors, wards, and operating theaters, were classified as having a high degree of clinic autonomy. They could handle most of their patient processes within their organizational boundaries without negotiating with other clinics.

1 point: Clinic size alone does not confer clinic autonomy; for example, a large emergency clinic with both an emergency room and ambulances has no clinic autonomy, because all its patients belong to someone else's clinical specialty, and improving an existing or introducing a new process entails cooperation with all specialties.

\section{Operationalizing of health care process quality (HPQ)}

The questionnaire to employees consisted of questions about resources and support for the manager, follow-up, improvement work and cost efficiency, care quality, health, engagement, and work satisfaction. We selected dimensions related to HPQ inspired by van den Heuvel et al. (2013), and used the following questions to create to measure output from the implementation of Lean or processes: 'To what extent do you feel that the work in your unit has improved over the last six months regarding ...', followed by these four statements: 'reduced delays and waiting times for the patient', 'increased efficiency (i.e., less wasted time)', 'the patient-care processes', and 'increased chances that patients receive timely care'. These questions were chosen because their aim is to measure process efficiency, the main aim of Lean or processes (Mazzocato et al., 2010). 
The response alternatives ranged from $1=$ there has been deterioration to $5=$ to a great extent (Cronbach's alpha $=0.88)$.

\section{Statistical methods}

The associations between managers' coaching style, preconditions, implementation strategy, appraisal of change and clinic autonomy (categorized from the qualitative data), and HPQ (assessed through employee questionnaires) was investigated stepwise. Descriptive statistics are presented in terms of percentages, mean, and standard error (SE). Assuming normally distributed data, we used one-way analysis of variance (ANOVA) to assess potential differences in group means with an alpha level of $\leq 0.05$ to indicate significant differences. We also analyzed the differences in HPQ means between T0 and T2, coupled to each variable, using the Tukey-Kramer test. The data were analyzed using JMP statistics 10.0.1.

\section{ETHICS}

Participation in the study was voluntary and confidential. Along with the survey, we sent out written information about the study. The study was approved by the Ethics Committee at Karolinska Institutet, Stockholm (ref: 2012/94-31/5).

\section{RESULTS}

\section{Distribution of managerial characteristics}

The categorization of the studied managers resulted in the following distribution: in the coaching style category, the single largest group was managers using integrated coaching; the second largest group was managers using immature coaching, closely followed by managers using a distanced coaching/dumping style (Fig. 1).

Among the managers, the positive-driving appraisal of change was most common, followed by positive-passive appraisal and then negative-passive appraisal. The studied group of managers contained more managers with poor than good preconditions, and most of the managers had no implementation strategy. Most of the studied managers were also responsible for clinics and departments with a low degree of clinic autonomy (Fig. 1).

\section{The importance of the manager's coaching style, appraisal of change, organizational preconditions, degree of clinical autonomy, and implementation strategy}

The differences in means between T0-T2 showed significant difference between, coaching style, organizational preconditions, and HPQ. The cross-sectional analyses revealed some associations between, appraisal to change, degree of clinic autonomy, implementations strategy, and HPQ. 
Figure I Distribution of the studied managers' characteristics in relation to the grading points, derived from assessing the interviews. The number in each bar is the total number of respondents in each category.

\section{Managerial characteristics}

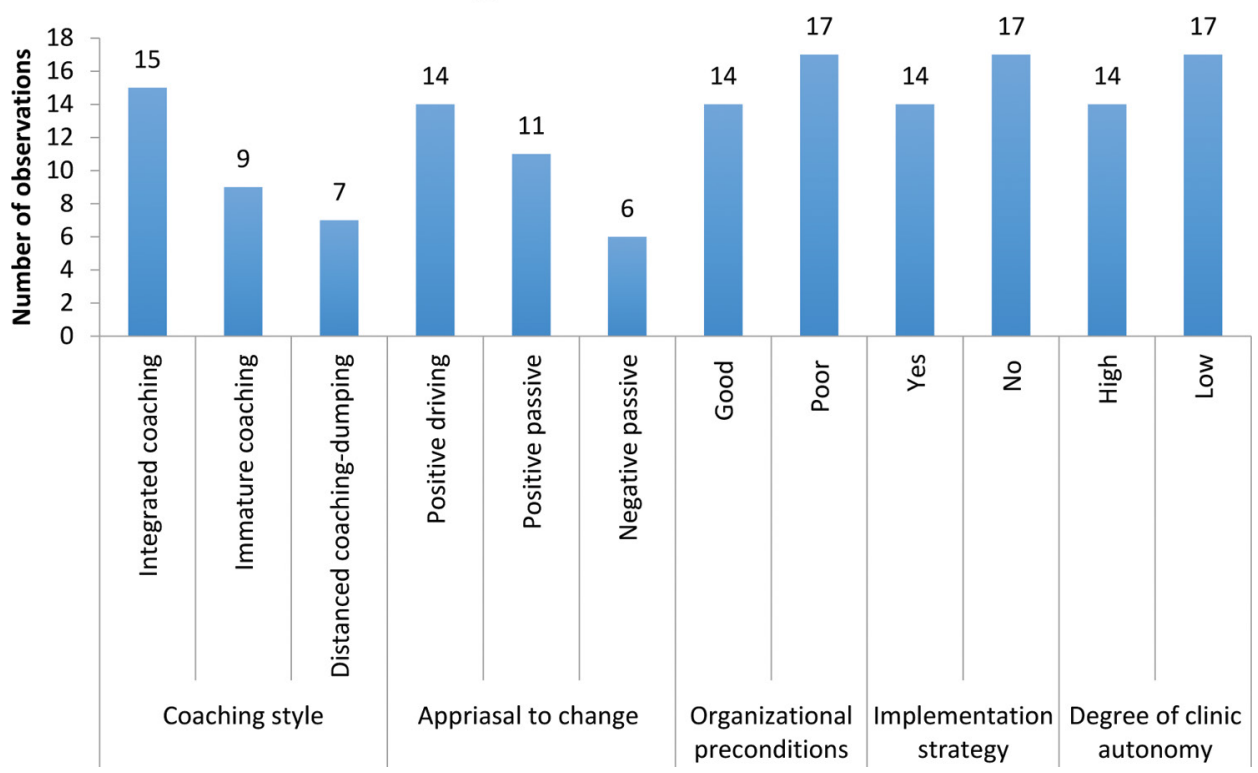

\section{Coaching style}

The analysis revealed that managers practicing integrated leadership or distanced coaching/dumping leadership both had better HPQ outcomes than managers practicing immature leadership, at both T0 (diff. 0.29 and $0.25, \mathrm{p}<0.001$ and $\mathrm{p}<0.01$, respectively) and T1 (diff. 0.37 and $0.26, \mathrm{p}<0.001$ and $\mathrm{p}<0.01$, respectively). On the last measurement occasion (T2), the managers practicing distanced coaching/dumping had higher estimated levels of HPQ than managers practicing immature coaching (diff. 0.29, $\mathrm{p}=0.028$ ) (Table 1). Furthermore, the analysis also found a significantly better outcome in HPQ for managers practicing distanced coaching/dumping than for managers practicing integrated coaching (diff. 0.34, $\mathrm{p}=0.022$ ). The outcome in terms of HPQ dropped for both groups over time (Table 2).

\section{Appraisal of change}

Managers with a negative-passive appraisal of change and managers with a positivedriving appraisal both had higher estimated levels of HPQ than managers with a positive-passive appraisal at T1 (diff. 0.20 and $0.19, \mathrm{p}=0.042$ and 0.013 , respectively). Furthermore, at T2, we also found indications of higher levels of HPQ for managers with a negative-passive appraisal of change than for managers with a positivepassive appraisal (diff. $0.27, \mathrm{p}=0.051$; results not in table). We could not detect any 
Table I Mean health care process quality (HPQ) values among managers classified by leadership characteristics, as well as analyses of differences (diff) based on one-way ANOVA at $\mathrm{TO}, \mathrm{TI}$, and $\mathrm{T} 2$

\begin{tabular}{|c|c|c|c|c|c|c|c|c|c|c|c|c|}
\hline \multirow[b]{2}{*}{ Coaching style } & \multicolumn{4}{|c|}{ HPQTO } & \multicolumn{4}{|c|}{ HPQTI } & \multicolumn{4}{|c|}{ HPQT2 } \\
\hline & $\mathbf{n}$ & mean & diff & $\mathbf{p}$ & $\mathbf{n}$ & mean & diff & $\mathbf{p}$ & $\mathbf{n}$ & mean & diff & $\mathbf{p}$ \\
\hline Distanced coaching (A) & 140 & 3.17 & $C-B$ & **** & 177 & 3.20 & $A-B$ & ***** & 112 & 3.08 & $A-B$ & * \\
\hline Immature coaching (B) & 208 & 2.92 & $A-B$ & **⿻丷木 & 185 & 2.83 & $C-B$ & ***** & 88 & 2.79 & $C-B$ & n.s \\
\hline Integrated coaching (C) & 310 & 3.22 & $C-A$ & n.s & 266 & 3.09 & $A-C$ & n.s & 210 & 3.00 & $A-C$ & n.s \\
\hline \multicolumn{13}{|l|}{ Appraisal of change } \\
\hline Negative passive $(A)$ & 119 & 3.09 & $C-B$ & n.s & 128 & 3.13 & $A-B$ & * & 93 & 3.10 & $A-B$ & n.s \\
\hline Positive passive (B) & 233 & 3.04 & $C-A$ & n.s & 239 & 2.93 & $\mathrm{C}-\mathrm{A}$ & $*$ & 104 & 2.83 & $C-B$ & n.s \\
\hline Positive driving (C) & 306 & 3.17 & $A-B$ & n.s & 261 & 3.12 & $A-C$ & **⿻丷木 & 213 & 2.99 & $A-C$ & n.s \\
\hline \multicolumn{13}{|l|}{ Preconditions } \\
\hline Poor preconditions (A) & 342 & 3.14 & $A-B$ & n.s & 347 & 3.12 & $A-B$ & * & 207 & 3.01 & $A-B$ & n.s \\
\hline Good preconditions (B) & 316 & 3.08 & & & 282 & 2.95 & & & 203 & 2.94 & & \\
\hline \multicolumn{13}{|l|}{ Clinic autonomy } \\
\hline No power $(A)$ & 409 & 3.04 & $B-A$ & **⿻丷木大 & 369 & 3.05 & $A-B$ & n.s & 215 & 2.97 & $A-B$ & n.s \\
\hline Power (B) & 247 & 3.21 & & & 250 & 3.04 & & & 192 & 2.98 & & \\
\hline \multicolumn{13}{|l|}{ Strategy } \\
\hline No strategy (A) & 323 & 3.05 & $B-A$ & n.s & 335 & 3.02 & $B-A$ & n.s & 181 & 2.93 & $B-A$ & n.s \\
\hline Strategy (B) & 335 & 3.17 & & & 293 & 3.07 & & & 229 & 3.01 & & \\
\hline
\end{tabular}

n.s: $=$ not significant, $*$ : $\leq 0.05, * *: p \leq 0.0$ I, ***: $p \leq 0.00$ I

Table 2 Results of one-way ANOVA, regarding differences (diff) between leadership characteristics and output in health care process quality (HPQ) over time (T0-T2)

\begin{tabular}{|c|c|c|c|}
\hline & \multicolumn{3}{|c|}{$\begin{array}{c}\text { Difference in HPQ } \\
\text { (T0-T2) }\end{array}$} \\
\hline & diff & SE & $\mathbf{p}$ \\
\hline \multicolumn{4}{|l|}{ Coaching style } \\
\hline Distanced vs. integrated & 0.34 & 0.13 & * \\
\hline Distanced vs. immature & 0.26 & 0.15 & n.s \\
\hline Immature vs. integrated & 0.07 & 0.13 & n.s \\
\hline \multicolumn{4}{|l|}{ Preconditions } \\
\hline Poor vs. good & 0.20 & 0.10 & * \\
\hline \multicolumn{4}{|l|}{ Implementation strategy } \\
\hline No vs. yes & 0.08 & 0.11 & n.s \\
\hline \multicolumn{4}{|l|}{ Appraisal of change } \\
\hline Negative passive vs. positive passive & 0.28 & 0.15 & n.s \\
\hline Negative passive vs. positive driving & 0.26 & 0.13 & n.s \\
\hline Positive driving vs. positive passive & 0.01 & 0.13 & n.s \\
\hline \multicolumn{4}{|l|}{ Clinic autonomy } \\
\hline Low degree vs. high degree & 0.19 & 0.10 & n.s \\
\hline
\end{tabular}

n.s: not significant, $*$ : $p \leq 0.05, * *: p \leq 0.01, * * *: p \leq 0.00$ । 
significant changes in the relationship between appraisal of change and HPQ over time (Table 2).

\section{Organizational preconditions}

Organizational preconditions seemed to be of importance only at T1, as employees of managers were classified as having poor preconditions and estimated higher levels of HPQ at T1 (diff. 0.17, $\mathrm{p}=0.013$; Table 1). Longitudinal analysis also revealed the same pattern, that is, managers with poor preconditions received higher estimated HPQ levels than managers with good preconditions did (diff. 0.20, $\mathrm{p}=0.049$; Table 1). However, the estimated HPQ levels decreased for both groups over time (Table 2).

\section{Degree of clinic autonomy}

Having a higher degree of clinic autonomy was of importance for higher estimated HPQ levels only at T0 (diff. $0.16, \mathrm{p}=0.08$; Table 1 ). We found no associations between degrees of clinic autonomy and HPQ over time.

\section{Implementation strategy}

There were indications of differences in HPQ between managers with and without implementation strategies at T1, when it seemed better to have a strategy (diff. 0.11, $\mathrm{p}=0.052$; Table 1). Over time, we found no associations between managers with or without implementation strategies (Table 2).

\section{DISCUSSION}

In this study, we found associations between managers' coaching style, appraisal to change, organizational preconditions, and implementation strategy, on the one hand, and HPQ, on the other hand. Coaching style and organizational preconditions also had importance for HPQ over time. This shows that the health care managers and their preconditions are important, factors during development work in health care.

Somewhat surprising was that over time, a more distanced coaching/dumping style yielded higher estimated HPQ outcomes than integrated coaching leadership did. This is possibly because managers who delegate responsibilities to implement, for example, Lean management to professional workers or employees can, sometimes achieve better results than managers with very active coaching styles (Mintzberg, 1983). For example, some of the distanced coaching/dumping managers were clear about their perceptions of Lean management and made it obvious that they had no intentions to implement it themselves. At the same time, Lean management or processes were something that hospital upper management wanted to see implemented. Lean management has a standard of encouraging teamwork and personal responsibility, so when implemented without too much steering from middle management, it could in fact give better results in 
terms of health care outcomes than implementation by a very active manager who wants to micromanage the professional workers' daily routines (Brunsson, 1996; Meyer \& Rowan, 1977; Mintzberg, 1983).

According to institutional theory, if a manager actually wants to implement an organizational reform, for example, Lean management, 'talking about' alone is not enough (Brunsson, 2006; Brunsson \& Olsen, 1993; Sederblad et al., 2013). Even a manager with a very sensitive coaching style could, according to our results, be counterproductive in implementation. The point is that Lean management is a standardized way to organize work, and the health care manager skill and knowledge of managing implementation is not always enough to reach successful implementation. It is sometimes better, especially when professionals workers are involved, to leave them alone to implement Lean management themselves. Without micromanagement, the outcomes will probably be better for the entire organization (Mintzberg, 1983). In this way, Lean management can be both implemented and not implemented at the same time, also referred to as being decoupled (Meyer \& Rowan, 1977). In their daily routines and how the professional workers are used to applying their skills, they can both control and organize their work without too much interference from the new management principles. The health care organization will therefore have implemented Lean to some parts successfully, according to the principle of decoupling its activities. This may partially explain why the distanced/ dumping coaching style management actually yielded significant results over time.

In the group of managers practicing a more distanced coaching/dumping, some clearly explained that if there was something in their department that needed to change, it was up to the employees to implement the change themselves. The fact that both integrated coaching and distanced coaching/dumping produced decreasing HPQ output over time signifies that successful change implementation could depend on finding a balance between management skills and delegating power to the professional workers or employees.

One important principle of Lean and related management principles is increasing the steering possibilities and allocating more responsibility to the employees. This principle should therefore fit professional workers in a hospital, as they are accustomed to high levels of autonomy and working according to well-established routines (Berlin \& Kastberg, 2013; Mintzberg, 1983). Successful implementation of Lean or process development requires that steering or management techniques be effective at actually inducing professional workers to experience that it is in their own interest to succeed in the implementation. According to Mintzberg (1983), it is not enough to implement a management concept without actually inducing the professional workers or employees to feel or experience that they have the main responsibility for implementing the concept themselves, even if they in fact are managed in doing so. Successful management or governance is dependent on the manager's competence at actually implementing the standardized way of applying, for example, Lean management. This entails working on implementation in small groups or teams, an approach that should suit professional workers such as doctors and nurses. The problem is thus that Lean management is not always actually implemented in practice, but is in fact only implemented partially or in the wrong way.

According to institutional theory, successful implementation of organizational change is sometimes only possible when organizations decouple their activities (Brunsson, 1996; DiMaggio \& Powell, 1983). This may also explain the lack of significant HPQ improvement results achieved by the studied managers with an active coaching style. The problem with such coaching is that if a manager tries to implement Lean 
management without actually doing so in an adequately sensitive manner, the results can be counterproductive, and may lead to decreased organizational efficiency instead.

The other significant finding of this study concerned the relationship between organizational preconditions and HPQ. The results indicate that HPQ dropped over time for both managers with good or with poor organizational preconditions and resources. However, the employees of managers classified as having poor preconditions experienced slightly better HPQ over time than did the employees of managers classified as having good preconditions. This might be because this group included managers who had renounced Lean management and processes and instead promoted their clinics' own development work, which may have been received positively by the employees, and thereby affected HPQ in a positive way. In this group, we also found managers of departments handling high patient volumes. In these cases, work on Lean management implementation and other change processes demanded considerable employee involvement starting from the bottom up, using certain tools and stressing incremental improvements facilitating daily operations. In this way, the employees receive quick feedback on what improvement methods really worked.

The lack of increase in HPQ over time could depend on the financially constrained environments in which the studied managers were working. Earlier research has demonstrated that managers working in such environments do not prioritize development programs; instead, they are focused on their units' core functions (Chuang et al., 2011). A previous study (Andreasson et al., 2015) also showed how the first and second-line managers tried to protect their own units from, decisions made from the hospital management, and that could affect their units in a perceived negative way. This can be of importance when interpreting the results, because the implementation of Lean and processes were initiated as top-down. Top-down approaches can be hard to implement in professional bureaucracies in which the involvement of professional groups is required in order to achieve sustainable change (Andreasson et al., 2015; Mintzberg, 1983; Rowe et al., 2005). According to Mintzberg (1983), one difficulty in implementing innovations in professional bureaucracies is professionals' reluctance to cooperate. This helps make professional bureaucracies inflexible structures that work well in producing standardized outputs, but have difficulties adapting to change and altering production methods. Professional bureaucracies with independent professionals have clear bottom-up decision-making mechanisms. This makes it difficult to apply change mechanisms to everybody, not just the strategic managers, as even the professionals must agree on the intended changes. This has meant that practical implementation varies considerably between hospitals; in some cases, it seems more important to claim to have implemented Lean management than actually to have implemented it in practice (Dellve et al., 2015).

\section{METHODOLOGICAL CONSIDERATIONS}

None of the variables, implementation strategy, appraisal to change, and degree of clinic autonomy, displayed a direct association with significant changes in HPQ over time, only at single measurement occasions. There are of course other factors that could have affected our result, as for example our classification of the managers characteristics, and our construction of the HPQ index. We did the classification of the health care managers according to certain characteristics based on the managers' answers about their 
approaches and strategies in implementing Lean management or process development. The HPQ output measure was based on questionnaire responses from the studied managers' employees, and there might be a discrepancy between the managers' statements in interview and what they managed to convey to their employees. The response rate to the questionnaires was fair (Rea et al., 1992; Roth et al., 1998), as the minimum response rate from a questionnaire must be at least $50 \%$. However, due to that the sample was different at T2, the response rate of $67 \%$ must be viewed in light of that.

During these three years, many other activities took place in Swedish health care, besides the implementation of Lean and processes that could affect the results of this study. For example, changes could have occurred in how the health care professionals perform their daily work, taking care of patients, upgrade their skills, and start with new treatment models in a successful way. Several other studies also show that successful implementation of Lean in health care is possible (Andersen et al., 2015; Dammand et al., 2014; Edwards et al., 2011; Kamp et al., 2016).

\section{CONCLUSION}

The conclusion from this study is that the health care managers' coaching style and their preconditions are important for their possibilities to work with and implement change, and there are several factors that can contribute or counteract this. One important contributing factor is that implementation of Lean and processes development requires involvement from the professional workers. They are in fact the experts in several areas of health care services and have valuable knowledge to contribute when it comes to improvement work. The fact that both integrated coaching and distanced coaching/ dumping produced decreasing HPQ output over time signifies that successful change implementation is dependent on finding a balance between management skills and delegating power to the professionals. It also seems that managers who renounce ideas from top management, and promote their own development ideas can be more successful in their development work than managers who translate top management ideas about Lean and processes and try to implement them. It also becomes clear that departments, which must interact with other departments to solve their high patient volumes, with poor preconditions, are more willing to try new methods as Lean to solve their problems.

Irrespective of which management principles are applied, the power to either participate in or counteract change is strong among health care professionals. Top-down implementation of Lean management is a risk in that the organization may only superficially imitate a management concept without internalizing its principles, meaning that the concept is not implemented in practice. We believe that health care managers and decision-makers need knowledge of whether and how various governance principles and management methods are compatible with professional bureaucracies such as health care organizations.

\section{References}

Andersen, K., \& Rövik, K.A. (2015) Lost in Translation: a case-study of the travel of Lean thinking a hospital. BMC Health Services Research (15) 401. doi: https:// 10.1186/s129130151081-z. 
Andersson, T., \& Liff, R. (2012) Does patient centred care mean risk aversion and risk ignoring? Unintended consequences of NPM reforms. International Journal of Public Sector Management 25 (4): 260-271. doi: https://doi.org/10.1108/09513551211244098.

Andreasson, J., Ahlstrom, L., Eriksson, A., \& Dellve, L. (2017) The importance of healthcare managers organizational preconditions and support resources for their appraisal of planned change and its outcomes. Journal of Hospital Administration 6(1): doi: https:// doi.org/10.5430/iha.v6n1p25.

Andreasson, J., Dellve, L., \& Eriksson, A. (2015) Healthcare manager's views on and approaches to implement models for improving care processes. Journal of Nursing Management 24(2): 219-227. doi: https://doi.org/10.1111/jonm.12303.

Arman, R., Wikström, E., Tengelin, E., \& Dellve, L. (2012) Work activities and stress among managers in health care. In Tengblad, S. (Eds.) The Work of Managers; Towards a practice theory of management (pp. 105-130). Oxford University press. New York. doi: https:// doi.org/10.1093/acprof:oso/9780199639724.003.0006.

Berlin, J., \& Kastberg G. (2011) Styrning av hälso- och sjukvaird [Governance of healthcare] Liber, Stockholm.

Bevir, M. (2012) Governance. Oxford University Press, Oxford.

Brunsson, N. (2006) The Organization of Hypocrisy. 2 nd edn. Liber, Stockholm.

Brunsson, N., \& Olsen, J. P. (1993) The Reforming Organization. Routledge, London and New York.

Charmaz, K. (2006) Constructing Grounded Theory; A practical guide through qualitative analysis. 11 th edn, SAGE publications. Great Britain, pp 2-208.

Chuang, E., Jason, K., \& Morgan, J,C. (2011) Implementing complex innovations: Factors influencing middle manager support. Health Care Management Review 36(4): 369-379.

Cummings, G.G., MacGregor, T., Davey, M., Lee, H., Wong, C.A., Lo, E., Muise, M. \& Stafford, E. (2010) Leaderships styles and outcome patterns for the nursing workforce and work environment: A systematic review. International Journal of Nursing Studies 47(3): 363-385.

Czarniawska, B. (2008) A Theory of Organizing. Edward Elgar; Cheltenham, UK/Northhampton, MA, USA.

Czarniawska., B. \& Sevón, G. (Eds.) (1996) Translating Organizational Change. Walter de Gruyter, Berlin/New York.

Damanpour, F. (1991) Organizational innovation: A meta-analysis of effects of determinants and moderators. Academy of Management Journal 34(3): 555-590. doi: https://doi. org $/ 10.2307 / 256406$.

Dammand, J., Hörlyck, M.., Jacobsen, T.L., Lueg, R., \& Röck, R.L. (2014) Lean Management in Hospitals: Evidence from Denmark.Administration of Public Management 23.

Dellve, L., Eriksson, A., Fredman, M., \& Kullen-Engström, A. (2013) Lean i hälso- och sjukvård [Lean in health care]. In Sederblad, P. (Eds.) Lean i Arbetslivet [Lean in Working Life] (pp.142-161). Liber, Stockholm.

Dellve, L., Williamsson, A., Strömgren, M., Holden, R.J., \& Eriksson, A. (2015) Lean implementation at different levels in Swedish hospitals: the importance of working conditions and stress. International Journal of Human Factors and Ergonomics 3(3-4): 235-253.

Demerouti, E., \& Bakker, A. B. (2011) The job demands-resources model: Challenges for future research. SA Journal of Industrial Psychology 37(2): 01-09. doi: https://doi. org/10.4102/sajip.v3 7i2.974.

DiMaggio, P. J., \& Powell, W. (1983) The iron cage revisited: Institutional isomorphism and collective rationality in organizational fields. Amercian Sociological Review, 48(2): 147160. doi: https://doi.org/10.2307/20951201.

Edling, C., \& Sandberg, A. (2013) New Management and Good Work? A Swedish Experience. In Sandberg, A. (Eds.) Nordic lights, Work, Management and Welfare in Scandinavia (pp. 384-405). SNS Förlag [SNS publisher]. 
Edwards, K., \& Nielsen, A.P. (2011) Improving Healthcare through Lean Management: Experiences from the Danish Healthcare system. Paper presented at $5^{\text {th }}$ Nordic Conference on Health Organization and Management, Frederiksberg, Denmark.

Glouberman, S., \& Mintzberg, H. (2001) Managing the Care of Health and the Cure of Disease - Part I: Differentiation. Health Care Management Review 26(1): 56-69.

Hall, P. (2013) NPM in Sweden: The risky Balance between Bureaucracy and Politics. In Sandberg, Å. (Eds.) Nordic lights, Work, Management and Welfare in Scandinavia (pp. 406-419). SNS Förlag [SNS publisher].

Holden, R.J. (2011) Lean thinking in emergency departments: a critical review. $A n$ nals of Emergency Medicine, 57 (3): 265-278. doi: https://doi.org/10.1016/j.annemergmed.2010.08.001.

Kamp, A., \& Dybbroe, B. (2016) Struggles of Professionalism and Emotional Labour in Standardized Mental Health Care. Nordic Journal of Working Life Studies (6), 67.

Kotter, J.P. (1996) Leading change. Harvard Business Press.

Lachinger. H. K. S., Purdy, N., Cho J., \& Almost J. (2006) Antecedents and consequences of nurse manager's perceptions of organizational support. Nursing Economics 24(1): 20.

Lee, S. Y. D., \& Alexander, J. A. (1999) Consequences of organizational change in US hospitals. Medical Care Research and Review 56(3): 227-276. doi: https://doi.org/10.1177/1 07755879905600301.

Mathena, K.A. (2002) Nursing manager leadership skills. Journal of Nursing Administration 32(3): 136-142. doi: https://doi.org/10.1097/00005110-200203000-00006.

Mazzocato, P., Savage, C., Brommels, M., Aronsson, H., \& Thor, J. (2010) Lean thinking in healthcare: a realist review of the literature. Quality and Safety in Health Care 19(5): 376-382. doi: https://doi.org/10.1136/qshc.2009.037986.

Meyer, J. W., \& Rowan, B. (1977) Institutionalized Organizations: Formal Structure as Myth and Ceremony. The American Journal of Sociology 83(2): 340-363. doi: http://web.unitn. it/files/download/12401/americal journal of sociology 831977 meyer.pdf.

Mintzberg, H. (1983) Structure in Fives. Designing Effective Organizations. Engelwood-Cliffs, CA, USA: Prentice-Hall.

Movitz, F., \& Sandberg, Å. (2013) Contested Models: Productive Welfare and Solidaristic Individualism. In Sandberg, Å. (Eds.) Nordic lights, Work, Management and Welfare in Scandinavia (pp. 31-90). SNS Förlag [SNS publisher].

Ohlsson, Ö., \& Rombach, B. (1998) Res Pyramiderna.[Raise the Pyramids] Svenska Förlaget. [Swedish publisher]. Stockholm.

Plsek, P.E., \& Wilson, T. (2001) Complexity science: complexity, leadership, and management in healthcare organisations. BMJ: British Medical Journal 323(7315): 746. doi: https:// doi.org/10.2307/2095101.

Rea, L.M., \& Parker, R.A. (1992) Designing and conducting survey research: A comprehensive guide. San Francisco, CA: Jossey-Bass, 1992.

Robertson, P.J., Roberts, D.R., \& Porras, J.I. (1993) Dynamics of planned organizational change: Assessing empirical support for a theoretical model. Academy of Management Journal 36(3): 619-634. doi: https://doi.org/10.2307/256595.

Roth, P.L., \& BeVier, C.A. Response rates in HRM/OB survey research: Norms and correlates, 1990-1994. Journal of Management Studies, 1998, 24, 97-117. https://doi.org/10.1016/ S0149-2063(99)80055-5.

Rowe, A., \& Hogarth, A. (2005) Use of a complex adaptive systems metaphor to achieve professional and organizational change. Journal of advanced nursing 51(4): 395-405.

Sandberg, Å. (Eds.) (2013) Nordic lights: Work, management and welfare in Scandinavia. SNS Förlag [SNS publisher].

Sederblad, P. (2013) Lean i arbetslivet. [Lean in working life] Liber. 
Skagert, K., Dellve, L., Eklöf, M., Ljung, T., Pousette, A., \& Ahlborg, G. (2008) Leadership and stress in public human service organizations: Acting shock absorber and sustaining own integrity. Applied ergonomics 39(6): 803-811.

Skytt, B. (2007) First-line nurse managers preconditions for practise: The important Interplay between person and organization (Doctoral dissertation, Uppsala University).

Tengblad, S. (2003) Den myndige medarbetaren- Strategier för ett konstruktivt medarbetarskap. [The employee authoritative- strategies for a constructive teamwork]. Malmö: Liber Ekonomi.

van den Heuvel, J., Niemeijer, G. C., \& Does, R. J. (2013) Measuring healthcare quality: The challenges. International Journal of Healthcare Quality Assurance 26(3): 269-278. doi: https://doi.org/10.1108/095526861311311454.

Vesterinen, S., Suhonen, M., Isola, A., \& Paasivaara, L. (2012) Nurse managers leadership styles in Finland. Nursing research and practice (2012. doi: https://doi. org/10.1155/2012/605379.

Weber, M., Henderson, A. M., \& Parsons, T. (1964) The Theory of Social and Economic Organization. Translated by AM Henderson and Talcott Parsons. Edited with an introduction by Talcott Parsons. New York; Collier-Macmillan: London.

Weimarsson, H. (2011) Nio av tio sjukhus har gått över till Lean. [Nine out of ten hospitals have switched to Lean]. Läkartidningen $\mathrm{nr} 39$. 